\title{
LEVERAGING BRAND COMMUNITIES IN SERVICE INNOVATION
}

\author{
Dhruv Bhatli, Université Paris Est, France \\ Tawfik Jelassi, ENPC MBA School of International Management, France
}

\begin{abstract}
Numerous earlier studies affirm the importance of services for corporations (Moller et al. 2008; Michel et al. 2008). Vargo and Lusch (2004) and Gronross (2007) identify service innovation and improvement as an important means to enhance market orientation and increase firms' success in terms of profitability, competitiveness and customer loyalty. However due to the specific characteristics of services (Djellal and Gallouj 2001; Menor et al. 2002) i.e., their intangibility, co-production with customers, simultaneity, heterogeneity and perishability (Fitzsimmons and Fitzsimmons 2000; Avlonitis et al. 2001) their development process is to a certain degree unique. As services primarily are processes that are simultaneously produced and consumed, these processes vary and so does the resulting output (Alonso-Rasgado et al. 2004). This complex, relatively intangible, constitution of services, together with the large range of service types, makes services difficult to relate to during new service development (Menor et al. 2002; Johne and Storey 1998). To counter the dynamic nature of services, some earlier studies support the integration of consumers in the service innovation process (Aa and Elfring 2002, Matthing et al. 2004). Matthing et al. (2004) state that 'Altogether, new service development relies on the difficult task of understanding and anticipating changing customer needs, with little help from traditional market research', laying emphasis on novel ways to articulate informal consumer knowledge. In this regard, Goffin and Mitchell (2005) and Juarasin (2010) distinguish between two components of innovation in services: service products (manner in which the services are produced and delivered to customers) and service augmetation (manner to ensure service quality, e.g. customer contact, quality of the contact and the serviscape or ambient conditions). These two components combine to form the augmented service offering, an important aspect of which is to incorporate clients experiences and capabilities, a shift from service provider to service co-creation paradigm, in line with the changing role of customers and the value of understanding their needs and problems steming from services. As more and more studies realise the potential of user knwoledge in service innovation, firms are faced with the dual challenge: (a) to identify relevant sources of user knowledge, i.e. from where to get consumer need information pertaining to service innovation, and (b) how to cater to consumers' expectations in the inhomogeneous and overcrowded market landscape with large array of products, i.e. to gather information efficiently about a large range of products. As consumer conversations shift online, one possible solution may be to listen to consumer discourses in the virtual space through monitoring the Brand Communities, which contain abundant brand related informal knowledge. Muniz and O'Guinn (2001) observe that these communities may be of special interest for firms as they behave as information sharing hubs for admirers of a particular brand or product and hold consumer conversations specific to one brand or product in a condensed and relevant form. Although many online platforms such as discussion boards, consumer forums, virtual communities etc. co exist, brand communities (BC) are likely to be the most relevant platforms to listen and engage consumers towards their service innovation efforts as they are formed and structured around a single brand or product, hence acting as information hubs, focused on a specific brand or product. This study intends to address this theme by exploring the potential of brand communities in the context of service innovation. To this objective, one brand community was identified and a ten-monthlong netnographic study was conducted. Netnography as research methodology was adopted as it is especially suited to study digitized consumer communities formed through Computer Mediated Communication (CMC). The study followed the nethnographic procedure drawn by Kozinets (2002). At the initial stage the community was observed in a non systematic manner, to become familiar with the particular culture and codes of the group, next the forums of the selected brand community were searched by key words, twenty individual and fifty combinations (e.g. service, store experience, home service, delivery, problem, after sales, experience etc.). In total over 8,000 messages were collected, coded and classified using NVIVO 9. The emerging themes form the basis of our findings, which suggest that monitoring brand communities can provide firms with consumer insights pertaining to (a) "service products", (b) quality of "service augmentation" in the serviscape, (c) efficiency of the customer contact, and (d) overall service experience on three levels: interpersonal service, remote service, and self-service. These insights can provide firms with informal consumer knowledge about their overall service experience, which firms can use to improve existing "service products" and the overall quality of "service augmentation" at all customer contact points in the serviscape.
\end{abstract}

References Available Upon Request

Proceedings of AMS' World Marketing Congress Cultural Perspectives in Marketing (C 2012 